ANIMAL BEHAVIOUR, 2006, 72, 199-207

doi:10.1016/j.anbehav.2006.01.010

Available online at www.sciencedirect.com

SCIENCE DIRECT

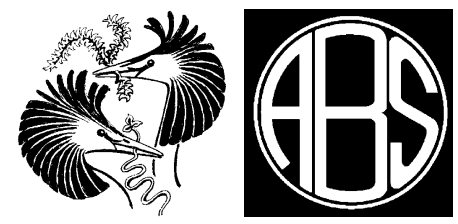

\title{
Physiological benefits as precursors of sociality: why banded geckos band
}

\author{
JENNIFER R. LANCASTER, PAUL WILSON \& ROBERT E. ESPINOZA \\ Department of Biology, California State University, Northridge \\ (Received 29 July 2005; initial acceptance 27 September 2005; \\ final acceptance 11 January 2006; published online 6 June 2006; MS. number: A10217R)
}

\begin{abstract}
Aggregating has been widely studied in a variety of animals and found to have important benefits in terms of sociality, courtship, predator avoidance and physiology. Several species of nocturnal geckos form diurnal aggregations; however, little is known about the benefits of these groupings. We conducted a series of experiments to determine the benefit of aggregation for the desert-dwelling western banded gecko, Coleonyx variegatus. We found that banded geckos benefit from aggregation by a reduction in evaporative water loss (EWL). No social or mating benefits were detected, and geckos did not group to avoid predators. Geckos did not select diurnal retreat sites based solely on the scent of conspecifics, although they aggregated readily when conspecifics were present. Thus, C. variegatus appear to achieve physiological but not social benefits from grouping. Banded geckos belong to an ancestrally tropical lineage whose descendants invaded present-day North American deserts at a time when these regions were more mesic. This may explain their relatively high rate of EWL. Aggregating seems to be a solution to this physiological handicap. Our study also suggests a path for the evolution of social behaviour: as animals aggregate for physiological benefits, the stage is set for the evolution of more complex social interactions.
\end{abstract}

(C) 2006 The Association for the Study of Animal Behaviour. Published by Elsevier Ltd. All rights reserved.

The formation of social aggregations is widespread in animals and can have important reproductive, ecological and fitness implications (Boersma 1982; Cohen \& Alford 1996; Avilés \& Turfiño 1998; Caro 1998). Some species aggregate to mitigate physiological stresses imposed by their abiotic environment, such as low moisture availability (e.g. Cohen \& Alford 1996) or thermal extremes (e.g. Boersma 1982; Shah et al. 2003; Bloomstein et al. 2004). Other species aggregate because of direct conspecific attraction, which can facilitate finding mates, defending resources and avoiding predators (Wilson 1971; Boersma 1982; Caro 1998; Krause \& Ruxton 2002; Spieler 2003).

An initial step in the evolution of social behaviour may be aggregation (Deneubourg et al. 2002), such as grouping within retreat sites. Although the vast majority of squamate reptiles (snakes and lizards) seem to be solitary most of the time and lack parental care (Shine 1988), at least a few are monogamous, forming long-term social bonds (Bull 2000; Chapple 2003). However, a more

Correspondence and present address: R. E. Espinoza, Department of Biology, California State University, Northridge, California 91330-8303,U.S.A. (email: robert.e.espinoza@csun.edu). J. R. Lancaster is now at the Department of Life Sciences, Pierce College, Woodland Hills, California 91371, U.S.A. commonly reported 'social behaviour' for squamates is aggregation within retreat sites. Several species of nocturnal geckos form diurnal aggregations (Greenberg 1943; Cooper et al. 1985; Burke 1994; Kearney et al. 2001; Shah et al. 2003); however, few studies have attempted to identify the cues these lizards use for aggregating or to measure the benefits of grouping. Shah et al. (2003) found that nocturnal thick-tailed geckos, Nephrurus milii, aggregate in their diurnal retreat sites. Grouping by these geckos was unaffected by adding the scent of a predatory snake (Pseudechis porphyriacus), and visual and chemical cues were insufficient to stimulate aggregation. Only when geckos were allowed physical contact with each other at low temperatures did aggregation increase. When in groups these large-bodied geckos ( $\sim 80 \mathrm{~mm}$ snout-vent length, SVL) achieved a higher aggregate thermal inertia than solitary geckos, which is important because $N$. milii live in relatively cool or thermally unpredictable climates, and occupy retreat sites that experience considerable temperature variation over the course of a day. Thus, these geckos apparently benefit physiologically by lengthening their time at elevated body temperatures (by reducing the rate of heat loss while in groups), but other social benefits were not reported.

Diurnal aggregation was first reported in the western banded gecko, Coleonyx variegatus (Eublepharidae), by 
Van Denburgh in 1922. Subsequent studies have shown that patterns of grouping, both in the field and laboratory, differ from random (Cooper et al. 1985; Burke 1994). Several biotic (e.g. attraction between conspecifics, reduction of predation risk) and abiotic factors (e.g. temperature conservation, moisture, physical dimensions of retreat site) have been suggested as reasons for grouping (Cooper et al. 1985; Kearney et al. 2001). Temperature and moisture tolerances are expected to be especially important to C. variegatus because, unlike their tropical eublepharid ancestors (Grismer 1988; Dial \& Grismer 1992), this species is distributed in the hot dry deserts of southwestern North America. From a physiological perspective, C. variegatus seem poorly suited to their desert environment. They are small-bodied (adults average $\sim 4 \mathrm{~g}$ ) and have lower body temperature preferences and higher rates of evaporative water loss than other sympatric desert lizards (Table 1). These apparently paradoxical findings might be explained by the moist-tropical phylogenetic roots of this species and the relatively recent warming and drying of its habitat.

The major northern and southern clades of eublepharid geckos were probably separated during the Early Pliocene by the Tehuántepec Portal. Members of the northern clade (present-day desert dwelling Coleonyx) were subsequently exposed to the drying trends that followed north of the Portal (Dial \& Grismer 1992). During the Late Pleistocene, the regions now recognized as the Sonora and Mojave deserts, where C. variegatus occurs, were piñon-juniper scrub (McAuliffe \& Van Devender 1998; Koehler et al. 2005), indicating lower temperatures and higher precipitation than present. Prior to and during the Pliocene, this region experienced substantially more precipitation (Axelrod 1979). For example, during the Lower Pliocene, the vegetation of the Anza Borrego Desert (eastern San Diego County, California), which is now dominated by desert shrubs (e.g. Ambrosia, Larrea) and cacti, matched the woodlands of present-day coastal ranges (e.g. Aesculus, Juglans, Umbellularia, as well as Juniperus and Sabal: Remeika 1994). Thus, in addition to exploring the evolutionary first steps of sociality, we sought to determine which aspects of the biology of banded geckos have responded to the challenges imposed by their warming and drying climate. From a behavioural perspective, banded geckos seem to avoid the extreme conditions of their environment by restricting their activity to nighttime and seeking refuge by day in well-insulated retreats such as rodent burrows, rock crevices or areas under large boulders (Van Denburgh 1922; Smith 1946; Stebbins 2003). Likewise, geckos may aggregate to compensate for their apparent handicap to this physiologically challenging environment. This line of reasoning assumes that grouping provides a physiological benefit.

There is little information on conditions favouring aggregation by banded geckos in the wild. Retreat sites might be selected based on specific conditions that few retreats provide (Burke 1994), leaving open the possibility that aggregation is an incidental result of a limited number of suitable retreats, rather than attraction to conspecifics per se. However, the finding that some geckos still group even when there is a surplus of burrows indicates that shelter availability alone does not account for the tendency to aggregate (Cooper et al. 1985). There is a greater tendency to aggregate when individuals are given a choice between preexisting burrows and a burrow that must be constructed on their own, suggesting an energy- or time-saving benefit (Cooper et al. 1985). Moreover, when in retreats, grouping geckos usually maintain physical contact with each other, even when there is ample space for them to avoid touching (Cooper et al. 1985; Lancaster 2005). This finding suggests that these lizards may benefit from grouping by reducing their effective surface-area-to-volume ratio, and thus lowering evaporative water loss (e.g. Cohen \& Alford 1996).

Given the multiple competing hypotheses for the evolution of aggregation, we performed a series of experiments that sought to determine the causes and benefits of aggregation in banded geckos. We first identified the abiotic and biotic factors that elicit grouping. Next, we measured how grouping influenced rates of evaporative water loss, a potential benefit of aggregation if water loss can be diminished by reducing surface area via gecko-togecko contact or if the group increases the relative humidity of the retreat. Finally, we tested how geckos respond to the odours of conspecifics and a predator in an

Table 1. Comparison of rates of evaporative water loss (EWL) and field body temperatures $\left(T_{\mathrm{b}}\right)$ of Coleonyx variegatus and sympatric lizard species

\begin{tabular}{|lccccc|}
\hline Species & Body mass $(\mathrm{g})$ & $\mathrm{EWL}(\mathrm{mg} / \mathrm{g} / \mathrm{h})$ & $\mathrm{EWL}$ temperature $\left({ }^{\circ} \mathrm{C}\right)$ & $T_{\mathrm{b}}\left({ }^{\circ} \mathrm{C} \pm \mathrm{SD}\right)$ & \multirow{2}{*}{$T_{\mathrm{b}}$ reference } \\
\hline Aspidoscelis tigris & 21.2 & 0.58 & 30 & $39.5 \pm 1.8$ & Pianka 1986 \\
Callisaurus draconoides & 12.7 & 0.40 & 30 & $39.1 \pm 2.6$ & Pianka 1986 \\
Coleonyx variegatus $\dagger$ & 4.7 & 0.91 & 25 & $28.4 \pm \mathbf{3 . 4}$ & Pianka 1986 \\
Crotaphytus collaris & 30.0 & 0.54 & 30 & 38.5 & Fitch 1956 \\
Dipsosaurus dorsalis & 47.9 & 0.37 & 30 & 37.4 & Cowles \& Bogert 1944 \\
Sauromalus ater & 140.0 & 0.22 & 26 & 37.7 & Cowles \& Bogert 1944 \\
Uma notata & 15.8 & 0.36 & $26-27$ & 38.6 & Brattstrom 1965 \\
Uma scoparia & 24.9 & 0.41 & 30 & $37.3 \pm 2.2$ & Pianka 1986 \\
Urosaurus ornatus & 3.1 & 0.30 & $25-27$ & $35.6 \pm 2.1$ & Pianka 1986 \\
Uta stansburiana & 3.3 & 0.46 & 27 & $35.3 \pm 2.4$ & Pianka 1986 \\
Xantusia vigilis & 1.1 & 0.41 & & $29.3 \pm 2.0$ & Pianka 1986 \\
\hline
\end{tabular}

*Data for EWL are from Mautz (1982) and Dial \& Grismer (1992).

$\dagger$ Coleonyx variegatus has a higher rate of EWL and lower $T_{\mathrm{b}}$ than other sympatric lizards, including smaller species. 
attempt to identify the cues used by these lizards when banding together. Our results illuminate two points of interest. First, they validate the idea that a first step toward social interactions might be for 'nonsocial' reasons. Second, as this species has adapted to an increasingly hot and arid environment, our results lead us to speculate about which aspects of banded gecko biology have changed more (behaviour) and which have changed less (anatomy and physiology).

\section{METHODS}

\section{Animals and Their Husbandry}

During 2002-2003, 33 banded geckos (15 adult males and 18 adult females) were collected from Borrego Springs, San Diego County, California, U.S.A. $(N=4)$; Etiwanda, San Bernardino County, California $(N=8)$; Palm Springs, Riverside County, California $(N=1)$; Owlhead Buttes, Pinal County, Arizona, U.S.A. $(N=5)$; and Eagle Eye Road, Maricopa County, Arizona $(N=15)$. Lizards were housed individually in plastic containers $(29.8 \times$ $19.0 \times 20.3 \mathrm{~cm}$ ) with all four sides covered with paper so that they could not view one another. Cages had a sand substratum with one retreat consisting of a circular ceramic dish $(10 \mathrm{~cm}$ diameter $\times 1.5 \mathrm{~cm}$ tall $)$ with an opening on one side. Each cage also had a plastic cup $(11.5 \mathrm{~cm}$ diameter $\times 4.5 \mathrm{~cm}$ tall) with an opening cut out and moist moss inside to provide a humid retreat to facilitate shedding. Heating pads placed at one end of each cage floor provided a thermal gradient $\left(\sim 25-43^{\circ} \mathrm{C}\right)$. Room air temperature was controlled by a thermostat set at $26 \pm 3^{\circ} \mathrm{C}$. Geckos were kept on a 10:14 h light:dark cycle during October-March and on an LD 14:10 h cycle during April-September, which roughly corresponds to the photoperiods they would experience in the wild. Lizards were fed crickets (Acheta domesticus) and mealworms (larval Tenebrio molitor) weekly. Water was provided ad libitum. All animals maintained or increased body mass and appeared healthy at the time of the experiments.

Two adult leaf-nosed snakes, Phyllorhynchus decurtatus, were collected in Borrego Springs, San Diego County, California, in 2003. These snakes are natural predators of C. variegatus, and both predator and prey occur sympatrically over most of their respective ranges (Smith 1946; Dial et al. 1989; Ernst \& Ernst 2003; Stebbins 2003). The snakes were housed individually in plastic containers $(29.8 \times 19.0 \times 20.3 \mathrm{~cm})$. They experienced the same photocycle as the geckos, and standing water was available ad libitum.

At the end of the study, the snakes were euthanized in accordance with the terms of our Institutional Animal Care and Use protocol and deposited in the California State University, Northridge herpetology collection (CSUN $2189,2194)$. The geckos were returned to the CSUN vivarium for additional studies.

\section{Ethical note}

Because the snakes were reluctant to eat and had to be force-fed most meals, they were kept at a lower temperature than the geckos $\left(\sim 23-25^{\circ} \mathrm{C}\right)$ to reduce feeding frequency and handling stress. The snakes were fed tails of laboratory mice, lizards (Sceloporus occidentalis, Uta stansburiana) and lizard eggs, including those of $C$. variegatus.

\section{Factors that Influence Aggregation}

\section{Role of conspecifics in aggregation}

To test the influence of the presence of conspecifics on aggregation, we offered groups of five geckos (two males and three females) a surplus of unscented retreats. Shelters consisted of circular clay dishes $(15.5 \times 2 \mathrm{~cm})$ large enough for multiple geckos to enter. Six shelters were equally spaced in a circular arena (122-cm diameter plastic 'kiddy pool') with a sand substratum (2-3 cm deep). Experiments were conducted overnight $(\sim 1500-1100$ hours) in the dark. The arenas were videotaped to monitor movements and interactions. The locations of the geckos were recorded at 1000-1200 hours the following morning (following Schlesinger \& Shine 1994; Downes \& Shine $1998 a, b)$. This experiment was tested in five trials, allowing 25 individuals to participate in each experimental treatment once. Individual geckos were randomly assigned to trials, and geckos were never in a group with the same individuals more than once. Geckos were fasted for at least 2 days and allowed free access to water before testing. Experiments were conducted during the breeding season (June-July 2004).

\section{Role of predators in aggregation}

To study the influence of perceived predator presence on grouping behaviour, we set up one large arena as described above. The arena contained six equally spaced, unscented retreat sites with the same temperature and humidity, but the arena had a small amount of faeces, shed skin and sand from a snake predator's (Phyllorhynchus decurtatus) cage haphazardly scattered about the substratum. All other experimental procedures were identical to the ones described for the conspecific-aggregation experiment. Trials were conducted during June-July 2004.

\section{Role of humidity in aggregation}

To test the influence of relative humidity on the tendency to aggregate, we placed geckos in large circular arenas as described above. The arenas had a surplus of retreat sites and were placed under domes made of opaque plastic sheeting stretched over a $1.9-\mathrm{cm}$ diameter PVCpipe frame to maintain either high $(\bar{X} \pm \mathrm{SE}=81 \pm 4.8 \%)$ or low $(37.1 \pm 11.1 \%)$ ambient humidity. The arenas were set on an elevated platform under which were five heating pads that maintained the substratum at mean \pm SE temperature of $20.0 \pm 1.9^{\circ} \mathrm{C}$. In the centre of the arena a humidifier (humid condition) or a dehumidifier (dry condition) was set on a circular elevated platform. Groups of four geckos (two of each sex) were introduced into arenas with six identical shelters. Five trials were run for each treatment (humid and dry). Individual geckos were randomly assigned to groups for each trial and geckos were never in a group with the same individuals more 
than once. Geckos were fasted for at least $24 \mathrm{~h}$ and allowed free access to water before testing. Experiments were conducted overnight ( 1600-1000 hours), and the locations of the geckos were recorded at 1000 hours the following morning (Schlesinger \& Shine 1994; Downes \& Shine 1998a, b). Trials were conducted during December 2004-January 2005.

\section{Water Economy and Aggregation}

\section{Conspecific contact and evaporative water loss}

We tested the hypothesis that geckos benefit from grouping by lowering their rates of evaporative water loss (EWL) by reducing their effective surface-area-tovolume ratio. We measured rates of EWL for geckos kept individually and in groups of two or three in mesh bags that allowed all surfaces of the geckos to be exposed to air except for where they were in contact with each other. Bags were made of nylon screen with 2-mm mesh, which varied in size $(\sim 7-11 \times 3-6 \mathrm{~cm})$ such that movement within the bag was minimized while exposing all surfaces of the lizard(s) to air. When in groups of two or three, the bag sizes ensured that geckos contacted each other (as they do in natural aggregations; Burke 1994). Prior to experiments, geckos were fasted for at least 2 days, yet always provided water. To estimate the rate of EWL, geckos were weighed $( \pm 0.01 \mathrm{~g})$ individually, placed into a screen bag, and held in a dark incubator at $29^{\circ} \mathrm{C}$ with $30-40 \%$ relative humidity. This temperature falls within the range experienced by geckos in nature (Vance 1973; Kingsbury 1989). The lizards were reweighed hourly for $8 \mathrm{~h}$ (0900-1700 hours). Individual EWL was estimated as the rate of mass lost per hour $(\mathrm{mg} / \mathrm{h})$. Each gecko was tested under three conditions: alone, in a pair, and in a group of three in random order three times for each of the three conditions. The lowest EWL value of the three was used for each individual for each group size $(1,2$ or 3$)$ to eliminate unreliable estimates of EWL resulting from urination, defecation or social interactions. The trials were conducted during July-September 2004.

\section{Grouping, relative humidity and evaporative water loss}

Natural retreat sites of geckos include rodent burrows and areas under large boulders (Van Denburgh 1922; Smith 1946; Stebbins 2003) with relatively narrow entrances. Therefore, we expected airflow to be limited within natural retreats. We tested the hypothesis that geckos benefit from grouping by lowering their rates of EWL by increasing the relative humidity of their retreat site via respiratory water loss. Individuals or groups of two or three geckos were placed in airtight plastic containers $(11 \times 7.5 \times 4.5 \mathrm{~cm}, 300 \mathrm{ml})$. Temperature and relative humidity were recorded by $\mathrm{HOBO}$ dataloggers (H08-003-02, Onset Computer Corp., Bourne, Massachusetts, U.S.A.), which were glued to the inside lid of each container. Hence the actual volume available to geckos within the containers was $240 \mathrm{ml}$. Geckos were kept in a dark incubator at $30^{\circ} \mathrm{C}$ for approximately $8 \mathrm{~h}(\sim 0900-$ 1700 hours) encompassing their diurnal inactivity period, and weighed at the beginning and end of each experiment to estimate EWL. As previously, each gecko was tested three times under three conditions in random order: alone, in a pair, and in a group of three. The lowest EWL value of the three was used as the final datum for each condition. Trials were conducted during October-December 2004.

\section{Aggregation Cues}

To test the hypothesis that geckos use integumentary and faecal chemical cues to select retreat sites, we presented male and female geckos with pairs of shelters, one of which was a control (unscented) retreat, the other of which was scented. The scents studied were from (1) conspecific males, (2) conspecific females, (3) the focal gecko's own scent and (4) the snake predator (Phyllorhynchus decurtatus; Dial et al. 1989).

Shelters consisted of inverted circular clay dishes $(10 \times 1.5 \mathrm{~cm})$. The shelter height was such that the reptiles made dorsal contact with the inside of the shelter (Downes \& Shine 1998a, b). Shelters were conditioned with scent from the treatment animals by placing the shelters with the scent donator for at least 5 days (modified from $\mathrm{S}$. Downes, personal communication). Between trials shelters were washed by thoroughly scrubbing them in hot soapy water, then soaking them in hot water for at least $30 \mathrm{~min}$. Shelters were then rinsed and soaked in clean water overnight and thoroughly dried (modified from Shah et al. 2003).

The experimentally treated shelter contained a small amount of faeces and/or shed skin from the scent donor to give the appearance of habitation and to strengthen the donor's scent. Geckos were introduced individually into a plastic cage $(29.8 \times 19.0 \times 20.3 \mathrm{~cm})$ with clean sand. One experimental shelter was randomly assigned to one end of the cage with a control shelter at the other. Cages were maintained in an environmental chamber with a daytime temperature of $30^{\circ} \mathrm{C}$ and a nighttime temperature of $25^{\circ} \mathrm{C}$ (Vance 1973; Kingsbury 1989). Each lizard was introduced into its enclosure in the mid- to late afternoon (1500-1600 hours) and checked the following day at about 1400 hours to determine the shelter it had selected for its diurnal retreat (following Downes \& Shine 1998a, b). This time interval incorporated the normal activity period of C. variegatus (Kingsbury 1989) and allowed the geckos to explore and choose retreat sites as they might in nature. Before testing, geckos were fasted for at least 2 days and provided access to water. Trials were conducted during the breeding season (April-May 2004).

\section{Statistical Analyses}

\section{Grouping experiments}

We used Morisita's index of aggregation (Hurlbert 1990) to test the distributions of geckos for departures from random. Morisita's index $\left(I_{M}\right)$ was calculated as:

$$
I_{M}=\frac{30\left(\Sigma x_{i}^{2}-\Sigma x_{i}\right)}{(\Sigma x)^{2}-\Sigma x_{i}}
$$

In an infinite arena, an $I_{M}=1$ would be obtained if animals all chose their retreats independent of each other, 
and increasing $I_{M}$ values indicate greater aggregation. The observed value of $I_{M}$ was compared to a distribution of 1000 randomized $I_{M}$ values. The mean number of geckos per retreat was always constant, and thus not a factor in comparing the $I_{M}$ values. A similar randomization test was performed on the data from the humid versus dry retreat-site experiments for which four geckos were used per trial. Additional analyses on the significance of aggregation are presented in Lancaster (2005).

We next compared the distribution among retreats when no snake scent was present versus when snake scent was present, and when the arena was humid versus dry to determine whether the distributions of treatments differed from each other in each of the two grouping experiments. We used a test of independence to compare the number of geckos (0-5) in shelters in nonscented versus snake-scented arenas. To avoid the assumption of large expected values, we used the exact module in SPSS (1998). The same procedure was used for the humid versus dry retreat-site selection experiment except that the number of geckos in a retreat ranged from zero to four.

Using all arena-grouping studies, we next tested whether males and females tended to be present together in a group more than expected by chance. This poses an analytical problem because the subject pool was a finite set of geckos (four or five) from which groups could be formed. Consequently, the formation of one group necessarily determines the composition of the next group to form. When more than one group resulted from a single trial, only one group was scored because the composition of the first group necessarily dictates the composition of the second group (e.g. if two male and two female geckos are present and a pair consisting of a male and a female forms, the remaining group must also be a male and female). For experimental trials that included five geckos, no trials had a group of three plus a group of two. There were seven trials of four geckos (humid versus dry experiment) that had one or two groups of two geckos. Each of these can be scored as either same-sex pairings or heterosexual pairings, which have equal probabilities of 0.5. There were seven trials with five geckos (snake-scent versus no-scent experiment) that resulted in groups of two or three geckos. Two of them had one group of two and three solitary geckos; for each of these trials, the probability of the pair being heterosexual was $(2 / 5) \times(3 / 5)+$ $(3 / 5) \times(2 / 5)=12 / 25$. In two other trials there were two groups of two geckos, and we randomly chose one of them to score, also with a heterosexual probability of $12 / 25$. There were three trials resulting in a group of three geckos and two individuals that did not group, with the corresponding probability of heterosexuality in the group being $13 / 25$. Overall, it is conservative to treat all of these probabilities as 0.5 . There were 14 informative trials, which were then subjected to a sign test to determine whether heterosexual groups were more common than same-sex groups.

\section{Evaporative water loss and aggregation}

For the experiments with geckos in screen bags and in enclosed retreats, ANOVA was used to study EWL (implemented in SPSS 1998). The ANOVA model tested for effects of group size, sex and group size $\times$ sex, but also took into account gecko subject nested within sex as a repeated measures factor. Additionally, linear regression was used to test for relationships between EWL and relative humidity for geckos in groups of three or two, or held individually in enclosed chambers.

\section{Aggregation cues}

Sign tests were conducted to determine whether geckos were choosing or avoiding treatment shelters in the paired choice experiments (Zar 1999). Fisher's exact test was used to determine whether males and females differed in response to predator-scented retreat choices.

\section{RESULTS}

\section{Factors that Influence Aggregation}

\section{Role of conspecifics in aggregation}

In arenas lacking snake scent, geckos grouped more frequently than expected at random $\left(I_{M}=2.300\right.$; randomization test: $P=0.026)$. In the snake-scented arenas, aggregation was weaker $\left(I_{M}=1.400\right)$, and the distribution of geckos did not differ from that expected by chance $(P=0.130)$. However, an exact test of independence failed to detect a difference in the strength of aggregation between nonscented and snake-scented distributions $(P=0.424)$.

Geckos aggregated in both the humid $\left(I_{M}=2.053\right.$; $P=0.008)$ and dry arenas $\left(I_{M}=1.579 ; P=0.053\right)$. Again, there was no significant difference between the distributions of group sizes (exact test of independence: $P=0.761)$.

Of the groups formed in all grouping experiments (no scent versus snake scent and dry versus humid), males and females were found together more often than expected by chance: 11 trials resulted in heterosexual groups and three trials resulted in same-sex groups (sign test: two-tailed $P=0.057)$. The three same-sex groups were all females, no all-male groups formed, and among the heterosexual groups, only one had two males and a female. Despite the potential for mating in heterosexual groups, none of the females became gravid after the trials.

\section{Water Economy and Aggregation}

\section{Grouping and evaporative water loss}

In mesh bags, there was no difference in rate of EWL when geckos were alone, in pairs or in groups of three (ANOVA: $F_{2,44}=1.094, P=0.344$; Fig. 1 ). However, females experienced higher rates of EWL than did males $\left(F_{1,22}=9.140, P=0.006\right)$ regardless of group size (interaction $F_{2,44}=2.278, P=0.115$ ).

\section{Relative humidity and evaporative water loss}

Figure 2 shows the results of EWL by group size for geckos experiencing different levels of humidity in enclosed retreats. Geckos in groups had lower rates of EWL than did single geckos (ANOVA: $F_{2,40}=36.633$, 


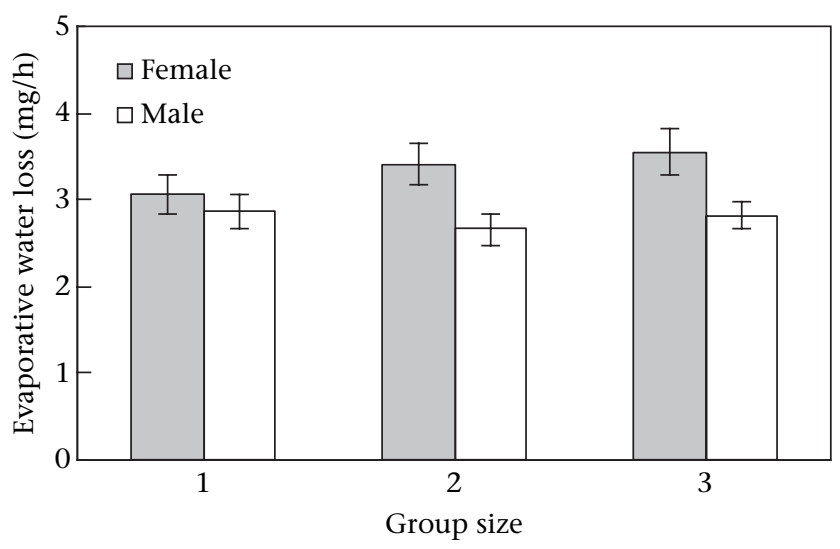

Figure 1. Rates of evaporative water loss (mean $\pm \mathrm{SE}$ ) for male and female Coleonyx variegatus when placed in mesh bags alone, in a pair and in a group of three. The same individuals were tested at each group size $(N=23)$.

$P<0.001$; Fig. 2). Retreat sites containing multiple geckos had a higher relative humidity than retreats with single geckos (ANOVA: $F_{2,40}=30.079, P<0.001$; Fig. 2 ). Retreats containing single geckos experienced a broad range of relative humidity (46.5-81.0\%), whereas groups of two geckos experienced a narrower range of relative humidity (63.1-84.6\%), and groups of three experienced an even narrower range (73.2-83.6\%). Single geckos lost more water with increasing relative humidity (linear regression: $\left.r^{2}=0.435, N=23, P<0.001\right)$, but geckos in groups of either two or three did not (two-gecko groups: linear regression: $r^{2}=0.007, N=22, P=0.721$; three-gecko groups: $r^{2}<0.001, N=23, P=0.973$; Fig. 3 ).

\section{Aggregation Cues}

Geckos did not show a preference for shelters scented by conspecifics (sign test: $P>0.5$; Table 2), nor did they choose shelters with their own scent more frequently than they did unscented shelters (sign test: $P \geq 0.1$ ). No

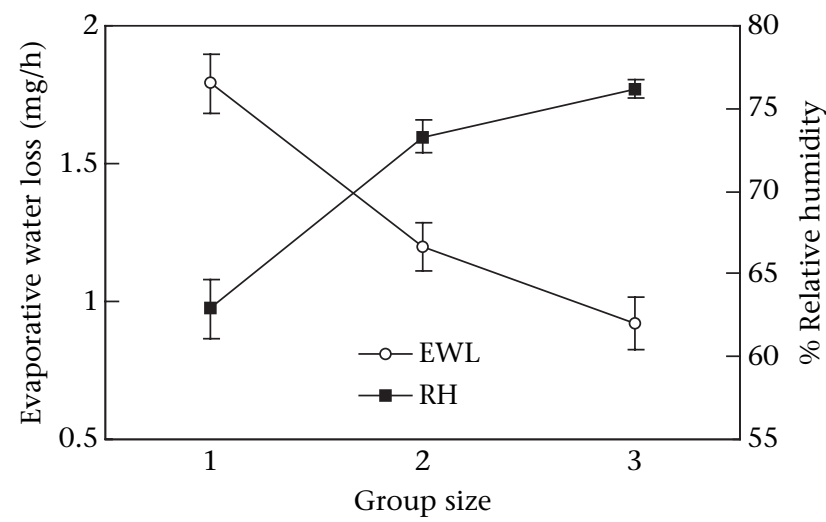

Figure 2. Rates of evaporative water loss (EWL; mean $\pm \mathrm{SE}$ ) for Coleonyx variegatus when placed in closed containers alone, in a pair and in a group of three. Relative humidity $(\mathrm{RH})$ for each group was averaged over the 8-h trial (following initial $\sim 1$-h temperature stabilization period). The same individuals were tested at each group size for both EWL and RH $(N=21)$.

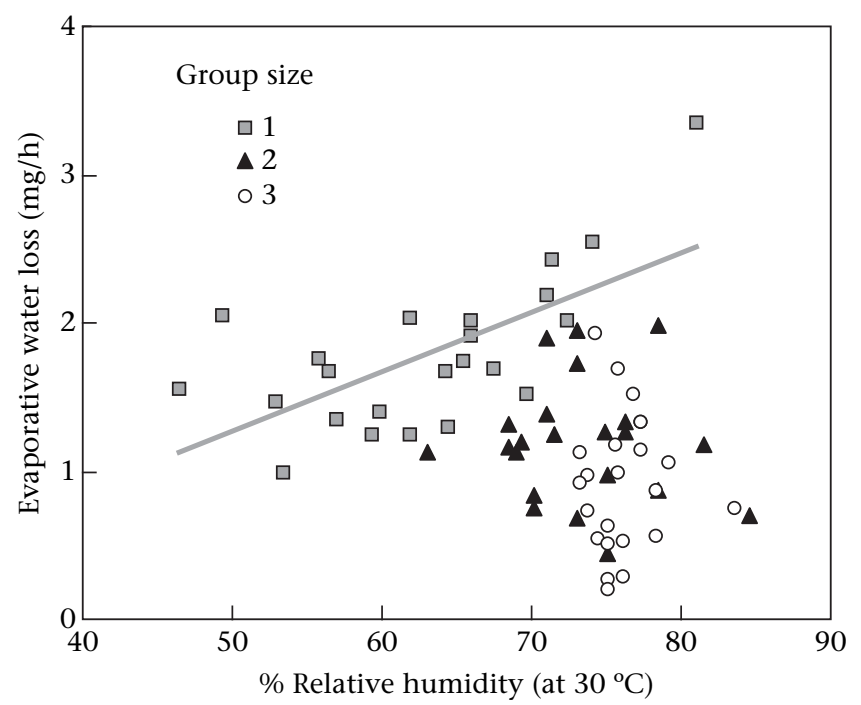

Figure 3. Rates of evaporative water loss (EWL) and within-retreat relative humidity $(\mathrm{RH})$ experienced by Coleonyx variegatus of different group sizes.

difference was found between males and females in response to predator scent (Fisher's exact test: $P=0.913$ ), so data for the sexes were pooled. From these data, it was apparent that geckos avoided predator-scented shelters (sign test: $P=0.004$; Table 2).

\section{DISCUSSION}

The experiments conducted here were used to evaluate several competing hypotheses regarding the benefits and proximate cues of social aggregation in C. variegatus (Table 3). The most strongly supported hypothesis for aggregation in C. variegatus is that grouping reduces EWL by increasing the humidity of the retreat sites used by geckos. Predator avoidance and retreat-site limitation were not supported (see also Cooper et al. 1985). The means by which $C$. variegatus aggregate appear to involve visual and/or physical contact with conspecifics, not just chemical cues, as noted for the distantly related gecko Nephrurus milii (Shah et al. 2003). The sex composition of the groups observed suggests that aggregation might facilitate

Table 2. Results of paired shelter comparisons

\begin{tabular}{|c|c|c|c|c|c|}
\hline \multirow[b]{2}{*}{ Gecko sex } & \multirow[b]{2}{*}{ Treatment } & \multicolumn{2}{|c|}{ Number choosing } & \multirow[b]{2}{*}{ Tails } & \multirow[b]{2}{*}{$P^{*}$} \\
\hline & & Treatment & Unscented & & \\
\hline Male & Male & 5 & 8 & 2 & 0.58 \\
\hline Male & Female & 5 & 8 & 2 & 0.58 \\
\hline Male & Self & 7 & 6 & 2 & 1.00 \\
\hline Female & Male & 8 & 7 & 2 & 1.00 \\
\hline Female & Female & 8 & 7 & 2 & 1.00 \\
\hline Female & Self & 5 & 10 & 2 & 0.30 \\
\hline Both & Self & 12 & 16 & 2 & 0.57 \\
\hline Both & Predator & 4 & 17 & 1 & 0.004 \\
\hline
\end{tabular}

*Sign test. 
Table 3. Summary of hypotheses, experiments and results for the factors influencing the cues used and the benefits accrued when forming diurnal aggregations in Coleonyx variegatus

Hypothesis Experiment(s) Results

A. Aggregation facilitates mating Groups of five geckos were placed together in an arena with six unscented shelters

Paired comparisons of female-, male- and self-scented shelters

B. Aggregation provides a predator-avoidance benefit

C. If aggregation lowers rates of evaporative water loss (EWL), geckos should not aggregate in humid environments

D. Aggregation lowers surfacearea-to-volume ratio, which lowers rates of EWL

E. Aggregation lowers rates of EWL by maintaining higher relative humidity within retreats occupied by more than one gecko

F. Mechanism: geckos use integumentary and faecal chemical cues to select retreat sites

G. Mechanism: geckos must be able to contact each other to elicit aggregation
Groups of five geckos were placed together in an arena with six shelters containing snake scent

Groups of four geckos were placed together in humid or dry arenas with six shelters each

Geckos were placed in screen bags in groups of one, two or three and maintained in an environmental chamber at constant temperature and humidity

Geckos were placed in closed boxes in groups of one, two or three and held at constant temperature

Paired comparisons of female-, male- and self-scented shelters

Groups of five geckos were placed together in an arena with six unscented shelters Paired comparisons of female-, male-, self- and predator-scented shelters
Male-female groups were more common than same-sex groups (sign test: $P=0.057$ ), but no successful matings occurred Geckos did not choose or avoid shelters scented by opposite-sex geckos (sign tests: $P>0.5$ for all)

Geckos did not aggregate significantly (randomization test: $P=0.130$ )

No difference in grouping between dry and humid arenas (exact test of independence: $P=0.761$ )

EWL did not depend on group size (ANOVA: $P=0.344$ )

Geckos in groups had lower EWL than solitary geckos (ANOVA: $P<0.001$ ) and maintained higher relative humidity within the retreat (ANOVA: $P<0.001$ )

Geckos avoided predator-scented arenas (sign test: $P=0.004$ ) but did not use conspecific scent to choose retreat sites (sign tests: $P \geq 0.5$ for all)

Geckos aggregated

(randomization test: $P=0.026$ )

Geckos did not use their own or other geckos' scent to choose retreat sites (sign test: $P \geq 0.5$ for all) pairing; however, no successful matings occurred during trials, so this hypothesis remains unsubstantiated.

Our experiments indicate that banded geckos derive more abiotic than social benefit from aggregation. They lowered their rates of EWL by grouping, but not because they lowered their effective surface-area-to-volume ratio. The mean difference in rates of EWL between geckos in pairs and geckos in groups of three was relatively small $(0.28 \mathrm{mg} / \mathrm{h})$, whereas the mean difference in rates of EWL between single geckos and geckos in pairs was twice that value $(0.59 \mathrm{mg} / \mathrm{h})$. If these data are extrapolated to compare the time interval required for a hypothetical 4-g gecko to lose $15 \%$ of its body water (approximately half to onethird the vital limit of most lizards; Mautz 1982), geckos in groups of two or three would take one or two weeks longer, respectively, to lose this amount than would solitary geckos (Lancaster 2005). This may explain why groups of two are the most common group size found in the field, although solitary geckos are even more numerous than pairs (Burke 1994). These insectivorous lizards (Smith 1946; Stebbins 2003) should be able to replenish water stores within a week (assuming prey availability) because insects are 50-90\% water (Chapman 1971). Moreover, because banded geckos do not normally live in high densities (Klauber 1945; Parker 1972), it may be sufficient for them to aggregate with a single conspecific rather than expending additional water and energy searching for others given the limited added benefit (Fig. 2). It is possible that geckos did not show a difference in aggregation behaviour across humidity treatments because (1) the dehumidifier did not induce a sufficient level of water stress and (2) humid conditions experienced in the field would be transient (e.g. a summer thunderstorm). Thus, geckos may aggregate with conspecifics even during humid periods in anticipation of imminent dry conditions.

\section{Evolutionary Significance of Aggregation}

Social behaviour is best viewed as a continuum (Krebs \& Davies 1993; Alcock 2001). At one extreme, animals benefit from grouping with conspecifics solely as a means of coping with abiotic challenges, with no social benefit. At the other extreme, animals interact with conspecifics in complex ways, obtaining benefits ranging from predator defence, more efficient acquisition of resources, mating, rearing of offspring, and so forth. Social behaviour can evolve along this continuum. If individuals initially benefit from aggregation physiologically, more complex social interactions may evolve because of the proximity to conspecifics.

Several species of Australian skinks (Egernia and Tiliqua spp.) show some of the most complex social behaviours 
known for squamate reptiles, including long-term social groupings, genetic monogamy and parental care (Bull 2000; Gardner et al. 2001, 2002; Chapple 2003; O'Connor $\&$ Shine 2003, 2004). Many of these species are largebodied and occupy thermally dynamic microhabitats, suggesting that a common benefit selecting for aggregation is the thermoregulatory advantage achieved by increasing thermal inertia. Once in contact with conspecifics, the complex social interactions (monogamy, parental care, etc.) could have evolved secondarily in these species. A similar scenario has been proposed for the evolution of sociality in animals as diverse as termites, herbivorous dinosaurs and ungulate mammals. Troyer (1982) found that hatchling green iguanas form temporary associations with older individuals, presumably for inoculation of gut microbes, which are needed for processing their plant diets. Troyer $(1982,1984)$ speculates that sociality in these groups was a necessary precursor to the evolution of herbivory because associations between hatchlings or newborns and older individuals facilitate exchange of microbial symbionts. Thus, grouping for the physiological benefit of digesting plants may have played a role in the evolution of more complex social systems, like those seen in ungulates.

In contrast to ungulates and monogamous Australian skinks, Coleonyx variegatus do not appear to reap a social benefit from aggregations. Instead, individuals experience a marked decrease in EWL when in groups. Thus, the advantages for $C$. variegatus appear to reside on the abiotic end of the behaviour continuum, where aggregation provides physiological but not social benefits.

Coleonyx variegatus live in hot dry deserts but experience substantially higher rates of EWL than other co-occurring lizard species (Table 1). This lineage of geckos first inhabited their current range when conditions were cooler and more mesic (Grismer 1988). As the temperature of the environment gradually increased and became more arid (Axelrod 1979), Coleonyx appear to have exhausted their physiological ability to limit EWL. Behavioural adaptations, including aggregating with conspecifics, may have followed from this apparent physiological constraint. This prediction could be tested further by determining whether tropical Coleonyx species (e.g. C. elegans and $C$. mitratus) aggregate in diurnal retreats. Given the physiological benefits of grouping, perhaps $C$. variegatus were released from strong selective pressure on traits that would further reduce EWL following the evolution of diurnal aggregation. In this sense, behaviour may function as a buffer that compensates for this apparent physiological constraint (see also Huey et al. 2003).

\section{Acknowledgments}

We thank W. Horn for help calculating probabilities for the grouping data, D. Gray for help with the experimental design, and D. Gray and M. Kearney for insightful comments on the manuscript. Thanks go to C. Rodriguez, E. Taylor, M. Feldner and J. Feldner for collecting geckos. J. Monzón, M. Hawthorne and R. Spengel built and assembled much of the equipment used in this study.
T. Uhlendorf and the staff of the California State University, Northridge (CSUN) Vivarium provided reliable care of the geckos. Funding was provided, in part, by the CSUN Graduate Thesis Support Program and Associated Students Student Project Committee Grant, the American Society of Ichthyologists and Herpetologists, Sigma Xi and the Society for Integrative and Comparative Biology. Animals were collected under state permit (Arizona HC351869, issued to M. Feldner, and California: SC-006582) and experiments were approved by the CSUN Animal Care and Use Committee (0203-005b).

\section{References}

Alcock, J. 2001. Animal Behavior. 7th edn. Sunderland, Massachusetts: Sinauer.

Avilés, L. \& Turfiño, P. 1998. Colony size and individual fitness in the social spider Anelosimus eximius. American Naturalist, 152, 403-418.

Axelrod, D. I. 1979. Age and origin of Sonoran Desert vegetation. Occasional Papers of the California Academy of Sciences, 132, 1-74.

Bloomstein, D. P., Im, S., Nicodemus, A. \& Zugmeyer, C. 2004 Yellow-bellied marmots (Marmota flaviventris) hibernate socially. Journal of Mammalogy, 85, 25-29.

Boersma, P. D. 1982. The benefits of sleeping aggregations in marine iguanas, Amblyrhynchus cristatus. In: Iguanas of the World: Their Behavior, Ecology, and Conservation (Ed. by G. M. Burghardt \& A. S. Rand), pp. 292-299. Park Ridge, New Jersey: Noyes.

Brattstrom, B. H. 1965. Body temperatures of reptiles. American Midland Naturalist, 73, 377-422.

Bull, C. M. 2000. Monogamy in lizards. Behavioural Processes, 51, 7 20.

Burke, R. L. 1994. Diurnal aggregation of banded geckos under field conditions. Southwestern Naturalist, 39, 297-298.

Caro, T. (Ed.). 1998. Behavioral Ecology and Conservation Biology. New York: Oxford University Press.

Chapman, R. F. 1971. The Insects: Structure and Function. 2nd edn. New York: Elsevier.

Chapple, D. G. 2003. Ecology, life history, and behavior in the Australian scincid genus Egernia, with comments on the evolution of complex sociality in lizards. Herpetological Monographs, 17, 145180.

Cohen, M. P. \& Alford, R. A. 1996. Factors affecting diurnal shelter use by the cane toad, Bufo marinus. Herpetologica, 52, 172-181.

Cooper, W. E., Jr, Caffrey, C. \& Vitt, L. J. 1985. Aggregation in the banded gecko, Coleonyx variegatus. Herpetologica, 41, 342-350

Cowles, R. B. \& Bogert, C. M. 1944. A preliminary study of the thermal requirements of desert reptiles. Bulletin of the American Museum of Natural History, 83, 265-296.

Deneubourg, J. L., Lioni, A. \& Detrain, C. 2002. Dynamics of aggregation and emergence of cooperation. Biological Bulletin, 202, 262-267.

Dial, B. E. \& Grismer, L. L. 1992. A phylogenetic analysis of physiological-ecological character evolution in the lizard genus Coleonyx and its implications for historical biogeographic reconstruction. Systematic Biology, 41, 178-195.

Dial, B. E., Weldon, P. J. \& Curtis, B. 1989. Chemosensory identification of snake predators (Phyllorhynchus decurtatus) by banded geckos (Coleonyx variegatus). Journal of Herpetology, 23, 224-229.

Downes, S. \& Shine, R. 1998a. Sedentary snakes and gullible geckos: predator-prey coevolution in nocturnal rock-dwelling reptiles. Animal Behaviour, 55, 1373-1385. 
Downes, S. \& Shine, R. 1998b. Heat, safety or solitude? Using habitat selection experiments to identify a lizard's priorities. Animal Behaviour, 55, 1387-1396.

Ernst, C. H. \& Ernst, E. M. 2003. Snakes of the United States and Canada. Washington, D.C: Smithsonian Books.

Fitch, H. S. 1956. Temperature responses in free-living amphibians and reptiles of northeastern Kansas. University of Kansas Publications, Museum of Natural History, 8, 417-476.

Gardner, M. G., Bull, C. M., Cooper, S. J. B. \& Duffield, G. A. 2001. Genetic evidence for a family structure in stable social aggregations of the Australian lizard Egernia stokesii. Molecular Ecology, 10, 175-183.

Gardner, M. G., Bull, C. M. \& Cooper, S. J. B. 2002. High levels of genetic monogamy in the group-living Australian lizard Egernia stokesii. Molecular Ecology, 11, 1787-1794.

Greenberg, B. 1943. Social behavior of the western banded gecko, Coleonyx variegatus Baird. Physiological Zoology, 16, 110-122.

Grismer, L. L. 1988. Phylogeny, taxonomy, classification, and biogeography of eublepharid geckos. In: Phylogenetic Relationships of the Lizard Families: Essays Commemorating Charles L. Camp (Ed. by R. Estes \& G. Pregill), pp. 369-469. Stanford, California: Stanford University Press.

Huey, R. B., Hertz, P. E. \& Sinervo, B. 2003. Behavioral drive versus behavioral inertia in evolution: a null model approach. American Naturalist, 161, 357-366.

Hurlbert, S. H. 1990. Spatial distribution of the montane unicorn. Oikos, 58, 257-271.

Kearney, M., Shine, R., Comber, S. \& Pearson, D. 2001. Why do geckos group? An analysis of "social" aggregations in two species of Australian lizards. Herpetologica, 57, 411-422.

Kingsbury, B. A. 1989. Factors influencing activity in Coleonyx variegatus. Journal of Herpetology, 23, 399-404.

Klauber, L. M. 1945. The geckos of the genus Coleonyx with descriptions of new subspecies. Transactions of the San Diego Society of Natural History, 10, 133-216.

Koehler, P. A., Anderson, R. S. \& Spaulding, W. G. 2005. Development of vegetation in the central Mojave Desert of California during the late Quaternary. Palaeogeography, Palaeoclimatology, Palaeoecology, 215, 297-311.

Krause, J., Ruxton, G. D. (Eds). 2002. Living in Groups. New York: Oxford University Press.

Krebs, J. R. \& Davies, N. B. 1993. An Introduction to Behavioural Ecology. 3rd edn. Oxford: Blackwell Scientific.

Lancaster, J.R. 2005. Why do banded geckos band? Identifying the causes and benefits of diurnal aggregation in Coleonyx variegatus. M.S. thesis, California State University, Northridge.

McAuliffe, J. R. \& Van Devender, T. R. 1998. A 22,000-year record of vegetation change in the north-central Sonoran Desert. Palaeogeography, Palaeoclimatology, Palaeoecology, 141, 253-275.
Mautz, W. J. 1982. Patterns of evaporative water loss. In: Biology of the Reptilia. Vol. 12 (Ed. by C. Gans \& F. H. Pough), pp. 443-481. New York: Academic Press.

O'Connor, D. E. \& Shine, R. 2003. Lizards in 'nuclear families': a novel reptilian social system in Egernia saxatilis (Scincidae). Molecular Ecology, 12, 743-752.

O'Connor, D. E. \& Shine, R. 2004. Parental care protects against infanticide in the lizard Egernia saxatilis (Scincidae). Animal Behaviour, 68, 1361-1369.

Parker, W. S. 1972. Aspects of the ecology of a Sonoran Desert population of the western banded gecko, Coleonyx variegatus (Sauria, Eublepharinae). American Midland Naturalist, 88, 209-224.

Pianka, E. R. 1986. Ecology and Natural History of Desert Lizards. Princeton, New Jersey: Princeton University Press.

Remeika, P. 1994. Lower Pliocene angiosperm hardwoods from the Vallecito-Fish Creek Basin, Anza-Borrego Desert State Park, California: deltaic stratigraphy, paleoclimate, paleoenvironment, and phytogeographic significance. San Bernardino County Museum Association Quarterly, 41, 26-27.

Schlesinger, C. A. \& Shine, R. 1994. Selection of diurnal retreat sites by the nocturnal gekkonid lizard Oedura lesueurii. Herpetologica, 50, 156-163.

Shah, B., Shine, R., Hudson, S. \& Kearney, M. 2003. Sociality in lizards: why do thick-tailed geckos (Nephrurus milii) aggregate? Behaviour, 140, 1039-1052.

Shine, R. 1988. Parental care in reptiles. In: Biology of the Reptilia. Vol. 16 (Ed. by C. Gans \& R. B. Huey), pp. 275-329. New York: Alan R. Liss.

Smith, H. M. 1946. Handbook of Lizards: Lizards of the United States and of Canada. Ithaca, New York: Comstock.

Spieler, M. 2003. Risk of predation affects aggregation size: a study with tadpoles of Phrynomantis microps (Anura: Microhylidae). Animal Behaviour, 65, 179-184.

SPSS. 1998. SYSTAT 9.0 Standard Version. Chicago: SPSS.

Stebbins, R. C. 2003. A Field Guide to Western Reptiles and Amphibians. 3rd edn. Boston: Houghton Mifflin.

Troyer, K. 1982. Transfer of fermentative microbes between generations in a herbivorous lizard. Science, 216, 540-542.

Troyer, K. 1984. Microbes, herbivory and the evolution of social behavior. Journal of Theoretical Biology, 106, 157-169.

Vance, V. J. 1973. Temperature preference and tolerance in the gecko, Coleonyx variegatus. Copeia, 1973, 615-617.

Van Denburgh, J. 1922. The reptiles of western North America. Vol. 1. Lizards. Occasional Papers of the California Academy of Sciences, 10, 1-611.

Wilson, E. O. 1971. The Insect Societies. Cambridge, Massachusetts: Belknap Press of Harvard University Press.

Zar, J. H. 1999. Biostatistical Analysis. 4th edn. Englewood Cliffs, New Jersey: Prentice Hall. 